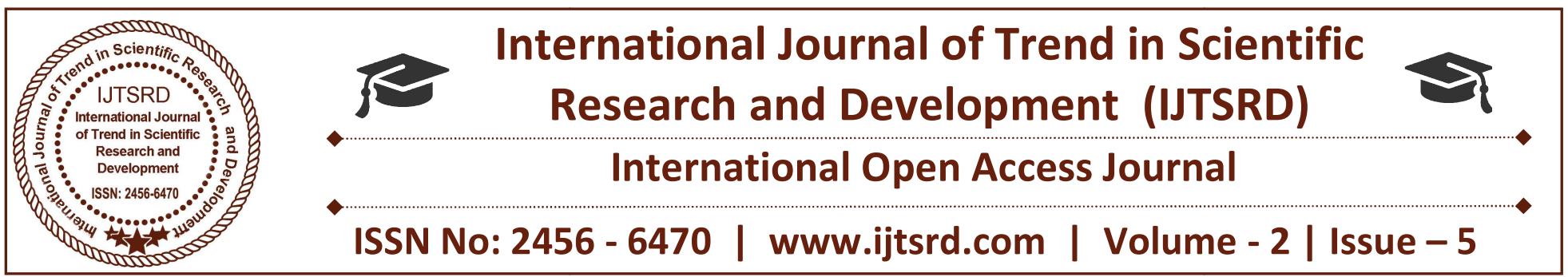

\title{
Should Marijuana be Legalized in India?
}

\author{
V.S. Krishna, Abhinov Vaidynathan \\ Shanmugha Arts, Science, Technology \& Research Academy \\ Thirumalaisamudram, Thanjavur, Tamil Nadu, India
}

\section{ABSTRACT}

Marijuana alludes to the dried leaves, stems, and flowers, seeds of the cannabis sativa or cannabis indica plants. These plants contain a mind-altering chemical known as THC. It contains about 400 chemicals and THC (delta-9-tetrahydrocannabinol) brings forth the psychoactive effect. Marijuana is the most frequently abused drug in the world. There are various methods of abuse with regards to marijuana such as it is usually smoked blunts, cigarettes, pipe, etc. Marijuana is also at times mixed with food and other edibles. Possession of marijuana is illegal in the majority of jurisdictions regardless of its purposes. Nonetheless, in certain countries, possession and usage of marijuana are legal for various purposes such as recreational purposes and medical purposes. In context to India, marijuana must not be legalized as it causes plenty of effects to the human beings which violates Article 21 of the Indian Constitution. Firstly, the authors in the research article would be dealing in detail with the overview of marijuana and its chemical components. Secondly, the methods of abuse would be dealt with in detail. Thirdly, the authors of the research article would be dealing with the short term and long term effects on the body and brain due to the usage of marijuana. Fourthly, the authors would be addressing the issue of whether marijuana can be legalized for medical purposes. During this submission, the authors with various references would be substantiating that marijuana does not suffice to medical necessity as it causes a lot of damage to the human body. The main thought process of the authors in the research article by referring to the above submissions is that marijuana must not be legalized in India.

\section{INTRODUCTION}

As we all are aware of Marijuana, a drug which affects the life of the people in numerous ways which a person can't imagine. Marijuana is a combination of dried greenish-gray flowers and leaves of cannabis sativa or cannabis indica plant which is smoked along with tobacco. Earlier, the cannabis sativa or cannabis indica plant was used for relieving the pain which occurred during the childbirth and for toothaches. The usage of the plant has been increasing in the modern era. The Cannabis Sativa and Cannabis Indica are originated in Central Asia of the Cannabaceae family. The effects and appearances generated from the plant are similar to each other. Some of the well-known scientists had made an attempt to prove that marijuana is a medicine and can be made legal but one of the main reason for its failure is that the unprocessed marijuana plants and crude extracts were not approved as a medicine to cure any diseases by the U.S. Food and Drug Administration. It has been proved that more than marijuana is used as a medicine for illness, it has been used as an illicit drug due to which people are falling ill. The reason behind the illness is the usage of a chemical namely 'Tetrahydrocannabinol (THC)' which affects the person psychologically when it is consumed. THC is the main mind-altering ingredient which is found in the cannabis plant. It has been established by the National Institute of Drug Abuse (NIDA) that the tetrahydrocannabinol acts as a cannabinoid chemical which is made naturally by the body. The cannabinoid chemicals i.e., the receptors are centralized in particular areas of the brain which is linked to thinking, memory, and pleasure, coordination and time perception. THC not only gets attached to these 
receptors but also activates them and affects the brain. A heavy dosage of marijuana can cause short-term as well as long-term effects. The U.S. Drug Enforcement Administration (DEA) after the serious discussion had decided marijuana to be a Schedule I drug such as heroin, LSD, and cocaine. Schedule I drugs are considered to be illegal due to the high abuse potential and safety reasons. Although it has been legalized in many countries for medical purposes the main motive for making it legal even though it is a Schedule I Drug has been declining due to increase in use for wrongful purposes. As per the report of the National Institute of Health (NIH), it has been found out that, soon after marijuana was legalized in many countries for recreational purposes, there was an immense rise in usage of marijuana in countries in which in which it has been legalized. The researchers at Columbia University's public health and medical center departments had found out from the National Survey of Drug Use and Health from 2004-2013 that the usage of marijuana kept on increasing over time by different age groups after it was legalized for medical and recreational purposes. There was the difference in the legalization of the said drug in different countries i.e., some countries legalized it for both medical and recreational purpose and some restricted itself to medical purpose only. It has been examined and proved that countries which have legalized marijuana for medical purposes have high 'Cannabidiol or CBD' substance which does not produce any psychoactive effects as compared to countries which legalized marijuana for recreational purpose where it has been established that the THC compound is more which provides the users a 'High'. As aforementioned, Countries which have legalized marijuana for both medical as well recreational purposes are Colorado, Washington, Alaska, Massachusetts, Oregon, Nevada, California, and Maine. Furthermore, Countries which have restricted itself for medical purposes only are Montana, North Dakota, Arizona, New Mexico, Arkansas, Louisiana, Florida, Illinois, Minnesota, Michigan, Ohio, New York, Pennsylvania, Maryland, District of Columbia, Vermont, New Hampshire, New Jersey, Rhode Island, Connecticut, Delaware and Hawaii. Researchers have stated that there is an increase in usage of marijuana among the adults of age 26 years where it has been raised from $4 \%$ to $6.59 \%$ compared to the teenagers (aged 18 to 25 years). They also ascertained that there is an annual increase in daily users of $2.36 \%$. Even though marijuana is legalized in various countries but there is no clear evidence that cannabis has been scientifically tested and can be used for medical purposes due to the restrictive laws. According to the Pew Research Center, in $1990,16 \%$ of the adults took into consideration that marijuana should be made legal and as on date, $53 \%$ of the adults believe that the aforesaid drug must be made legal. In addition to that, the White House Office of National Drug Control Policy has stated that people get easily enticed to use marijuana at the age of 17.5 years and also nearly half of the American people i.e., $49 \%$ of the Americans have used marijuana at least one time in their lifetime. This clearly demonstrates the number of people that are influenced by the usage of the drug and wants it to be legalized regardless of the repercussions that it may cause to one.

\section{METHODS OF ABUSE AND ITS EFFECTS}

When marijuana is smoked, THC travels from the lungs through the bloodstream to various organs of the body including the brain. The body draws up THC slowly when it is mixed with food or other edibles. In the brain, the THC affixes to particular cites called cannabinoid receptors on nerve cells and affect the activity of those cells. Most of the receptors are found in the brain that brings forth pleasure, thought, concentration, $C$ sensory and time perception, concentration, etc. Furthermore, the authors would like to deal with the aspect of short term and long term effects of marijuana on mind, body and other effects. Firstly, marijuana causes plenty of short-term effects on the mind of the person such as problems with learning and memory, problem-solving and difficulty in thinking, altered sense of time, change in mood, hallucinations, delusions, impaired body movement, psychosis, loss of coordination, etc. Secondly, Usage of marijuana causes various shortterm physical effects which include increased heart rate, increased appetite, decreased blood pressure, sedation, blood shot eyes, coughing due to lung irritation. Similar to the tobacco smokers, even the marijuana smokers encounter serious health issues such as emphysema, bronchial asthma, and bronchitis. Elongated use may cause a subduing effect on the immune system. Marijuana contains carcinogens and toxins which might lead to cancer of the neck, lungs, head and respiratory track.

Long-term chronic usage of marijuana causes effects associated with impairment of judgment, characterized by apathy, A motivational syndrome, memory and concentration and loss of interest, motivation, ambition with regards to personal goals. 
Extended usage of high doses of marijuana might result in panic reaction and mental confusions. Longterm usage of marijuana affects brain development which affects the brain to build connections between the areas essential for their functioning. Marijuana increases the heart rate by up to three hours after smoking. This increases the risk of heart attack. Frequent, long-term usage of marijuana leads to Cannabinoid Hyperemesis Syndrome. This brings about regular cycles of intense nausea, dehydration, vomiting which at times would need immediate medical attention. Furthermore, Long-term usage of marijuana has led to serious mental illness in some people such as schizophrenia - a critical mental disorder with certain symptoms such as paranoia and disorganized thinking. A research study was conducted in New Zealand by researchers at Duke University on the effects of usage of marijuana on the IQ an individual. It showed that they lost an average of 8 IQ points between ages 13 to 38 . The study also showed that the lost mental abilities did not return for those who quit the usage of marijuana as adults. Long-term usage of marijuana extensively impairs judgment, reaction time and coordination - these are the important skills to drive safely. As per various studies driving under the effect of marijuana increases the accident risks by $92 \%$ and they are 3 to 7 times more likely to have a car crash as their under the influence of the psychoactive substance.

In the case of Shyam Singh vs State of M.P. ${ }^{2}$ accused was a young man and was addicted to drugs. He was unemployed and needed money to keep up with his habit. The accused used to often smoke marijuana and he used to forcefully borrow money from his father. The accused had committed a triple murder which included his parents and another person in a brutal manner. It was argued that the addiction towards drugs made him react that way keeping in mind that he also belonged to a deprived socioeconomic background.

\section{REASONS TO NOT LEGALIZE MARIJUANA IN INDIA}

Legalization of medical marijuana as well as regularizing of cannabis and opium in India would not be considered by the Parliament in the near future as it

\footnotetext{
${ }^{1}$ Meier MH, Caspi A, Ambler A, et al. Persistent cannabis users show neuropsychological decline from childhood to midlife. Proc Natl Acad Sci U S A. 2012; 109(40):E2657E2664.doi:10.1073/pnas.1206820109.

would as act as an amendment to the Narcotic Drugs and Psychotropic Substances (NDPS) Act of 1985. As compared to the Indian laws and economy, U.S. Laws are entirely different in connection with legalizing medical marijuana. If a bill is to be passed on legalizing medical marijuana in India, it would have a tremendous effect on Indian society and would most likely take years of red tape and research before THC or $\mathrm{CBD}$ products would meet the legal Indian market. ${ }^{3}$ Marijuana was legal in India prior to the Narcotic Drugs and Psychotropic Substances (NDPS) Act of 1985 came into force. The first-ever international treaty which had clubbed cannabis (also known as marijuana) with hard drugs was in 1961 which was called as 'single convention on narcotic drugs' where it had imposed a ban on the production and distribution of the drug except for medical and research purposes. At the time of negotiations for the UN treaty which was signed by New York, a group led by India which included countries producing cannabis and opium had opposed that it couldn't tolerate the socio-cultural use of organic drugs. During this era, most of the states in the US had banned the usage of all narcotic drugs while India was focusing on the restrictions to be imposed on the harder substances like opium. Based on the traditional consumption of drug in India and considering the social aspect, the UN had given 25 years to eradicate the usage of such drugs in India for any purposes bearing in mind the harmful effects it would lead one too and ruin one's life after the using the drug. At the end of 1961, the Indian Government which was popularly recognized as the Rajiv Gandhi Government had given confirmation on the 'Single Convention on Narcotic Drugs' treaty where Narcotic Drugs and Psychotropic Substances (NDPS) Act of 1985 was enacted which made possession and usage of marijuana illegal in India. The NDPS Act has made it very clear regarding the punishment that would be levied on a person regarding marijuana:-

Cannabis has been defined under Section 2 (iii) of the Narcotic Drugs and Psychotropic Substances Act of $1985^{4}$, Cannabis (hemp) means -

A. Charas, that is, the separated resin, in whatever form, whether crude or purified, obtained from the cannabis plant and also includes

\footnotetext{
${ }^{3} \mathrm{https}$ ://www.dopemagazine.com/india-legalize-cannabis/

${ }^{4}$ https://indiankanoon.org/doc/1445793/
} 
concentrated preparation and resin known as hashish oil or liquid hashish.

B. Ganja, that is, the flowering or fruiting tops of the cannabis plant ( excluding the seeds and leaves when not accompanied by the tops ), by whatever name they may be known or designated, and

C. Any mixture, with or without any neutral material, of any of the above forms of cannabis or any drink, prepared there from.

As per Section 20 of the NDPS Act, 1985 which states the repercussions for the offenses associated not only with the consumption but also cultivation, possession, use, sale or purchase, import or export, transportation and warehousing of cannabis.

One who is caught cultivating the plant would be given rigorous imprisonment for a term of 10 years and a fine of up to one lakh rupees.

$>$ One who possess small quantities of marijuana i.e., up to 100 grams of Charas and Hashish and 1 $\mathrm{kg}$ of marijuana, would be imprisoned for a term of 6 months to 1 year and a penalty of Rs. 10,000 would be imposed.

$>$ One is possessing commercial amount i.e., up to 1 $\mathrm{kg}$ of charas and $20 \mathrm{~kg}$ of marijuana, would be imprisoned for a term of 20 years and also a fine of Rs. 2 lakh would be imposed.

$>$ One who is in regular use of the drug i.e., who is a regular offender would be punished by the discretion of the Court but would be imprisoned for a term which might extend to 30 years.

Under Section 25 of the NDPS Act of 1985 which states that One who knowingly permits any kind of dealings nearly related or which is directly related to the drug in his premises would be imprisoned for a term of 10 years and also a fine of Rs. 1 lakh would be imposed.

As per Section 28 and 29 of the NDPS Act of 1985 which deals with the punishment for attempts, abetment and criminal conspiracy in connection with marijuana.
The laws pertaining to marijuana may vary from one state to another as we are well aware of the fact that the power to control, permit and regulate such illicit activities differs. Although many countries have legalized marijuana for medical and recreational purposes it doesn't mean that India needs to follow the same and repent later when we know the repercussions of the drug when it is used. In Uttar Pradesh, the rules have been excised in such a way that there will be a imprisonment for a term of 2 years and also fine would be imposed if:-

Any type of intoxicant is imported, exported, transported or possessed.

Any kind of hemp plant is cultivated i.e., Cannabis sativa.

Anyone collects or sells any portion of the hemp plant.

Anyone collects or sells any portion of hemp plant which can be used for manufacturing any intoxication drug.

Elements of the marijuana plant might have medicinal properties, but it is not identical to medicines. The expression 'Medical Marijuana' is used time and again to the unprocessed marijuana plant or its extracts; these are neither approved nor recognized as medicine by the Central Drugs Standard Control Organization, U.S. Food and Drug Administration for treatment of any illness. Marijuana is being marketed as a medicine in the market which has changed the perceptions towards marijuana. Nonetheless, the basic features and facts of marijuana do not change as discussed previously about the various effects due to the usage of marijuana. There is a lot of debate on legalization of marijuana, legalizing marijuana does not equal safety. There are certain arguments for the legalization such as cigarettes and alcohol is legal despite of health risks. It is humbly submitted by the authors that we must look at those number of people combating alcohol addiction or ailments with regards to alcohol abuse. The International Narcotics Control Board (INCB) issued a statement persisting the other countries to contemplate the factual dangers of cannabis. The statement is as follows 'Cannabis is classified under the international conventions as a drug with a number of personal and public health problems. It is not a 'soft' drug as some people would have you believe. There is new evidence confirming 
well-known mental health problems, and some countries with a more liberal policy towards cannabis are reviewing their position. Countries need to take a strong stance towards cannabis abuse'.

The authors would be putting forth various opinions in the medical community which do not accept smoked marijuana as a medicine:

The National Multiple Sclerosis Society (NMSS) has asserted that medical marijuana could not be recommended to be widely available for persons with multiple sclerosis with regards to management. This was asserted by them because the studies till now do not indicate an explicit benefit and more importantly the long-term effects, side effects, etc. are not clear until now.

The American Cancer Society (ACS) does not endorse inhaling smoke, nor the legalization for the usage of marijuana due to its various effects on the human mind and body.
The British Medical Association (BMA) asserted their utmost concern that by demoting the criminal status of marijuana, there are chances for the public to get mislead to believe that the drug is safe. The BMA have stressed about the greater risk linked between the usage of marijuana and the effects such as heart attack, bronchitis, lung cancer and emphysema. In the year 2004, the Deputy Chairman of BMA's Board of science mentioned that the people must be made informed about the various harmful effects of the usage of marijuana.

\section{CONCLUSION}

Based on the above criticisms about marijuana and its medicinal purposes it is clearly evident that they are not advisable for any kind of usage as it does not serve the purpose. The authors of the research article humbly submit that the usage of marijuana for recreational or medical purposes would only cause greater implications rather than serving as a remedy for various diseases ought to be mentioned. In order to conclude, the authors assert through this research article to not legalize the usage of marijuana in India.

\footnotetext{
5"INCB: US Supreme Court Decision on Cannabis Upholds International Law." Professor Hamid Ghodse, President of the INCB. Press Release. June 8, 2005.
} 